\title{
Reaching Self-actualization in Education: Construction and Validation of a Hierarchical Scale
}

\author{
Zahra Barzakhi Farimani \\ Ferdowsi University of Mashhad, Iran \\ Navid Nasrollahi Shahri \\ Shiraz University, Iran
}

\begin{abstract}
The present study aimed to adapt and validate the Maslow's Hierarchy of Needs in the EFL settings of Iranian universities. A review of the related literature showed that there are very few studies on the application of Maslow's hierarchy of needs in learning contexts, especially that of foreign/second language classes. To do so, having revised and rephrased the items in the scale developed for Hierarchy of Needs, the researcher made sure of the content validity and reliability of the revised version. Afterwards, the designed questionnaires were distributed among 271 learners of language studying at Ferdowsi, Imam Reza and Tabaran universities. The obtained data were then analyzed. Confirmatory factor analysis procedures were held to ensure the construct validity of the questionnaire. The designed scale was validated through certain statistical procedures. Confirmatory Factor Analysis and content validity procedures were done to ensure the validity of the scale. In addition to this, using Coranbach's coefficient of reliability, the items and the scale as a whole were proven to be reliable. The significance of the work lies in the fact that the better an educator knows their own students, the better rapport they can establish with them. This can to a great extent improve the teaching and learning process in different contexts. It is to be said that this scale can be of great significance in any kinds of research in the field that deals with needs and expectations of students at different levels.
\end{abstract}

Index Terms - motivation, hierarchy of needs, Maslow's theory, satisfaction, EFL context

\section{INTRODUCTION}

According to the humanistic perspective, the purpose of education, in general, is known to be providing a sound foundation for personal development, in a way that learning keeps going on throughout our life in automatic fashion. When we look at Maslow's hierarchy and its eight stages, we can easily understand the impact, value and importance in what it can bring out in the educational process of students and their success. It is widely known that the better a teacher knows his/her own student, the better rapport he/she can establish with them. This can to a great extent improve the teaching and learning process. A challenge that most teachers deal with in English classes is to find out about the needs of their students. The present study aims to revise and validate the hierarchy of needs that was proposed by Maslow, through which we will be provided with significant information on the motivations and needs of students in an EFL setting. Accordingly, the research problems are presented, and the research questions are introduced. The main objective of this study is to establish an understanding of how best to proceed in studying this issue by gathering information and establishing a scale through a revision and validation process. There are numerous studies on the needs and motivations of students from different points of views. Consequently, several studies have also discussed the needs of people from the perspective of psychology. In this regard, it is to be mentioned that Maslow's hierarchy of needs is actually used in different studies. However, there are very few, if any, studies on the application of Maslow's hierarchy of needs in classes, particularly foreign/second language classes in the framework of Maslow's hierarchy. More importantly, students' needs seem to be, to a great extent, neglected in research studies, especially those conducted in Iran.

\section{Research Question:}

1. Does the scale measuring Maslow's hierarchy of needs in EFL learning contexts enjoy content validity?

2. Does the scale measuring Maslow's hierarchy of needs in EFL learning contexts enjoy construct validity?

3. Is the revised scale measuring Maslow's hierarchy of needs reliable?

4. Does one's gender, learning background, age and score average of learners play any roles in the needs of students in EFL contexts?

5. What are the corresponding needs of students in English learning classrooms according to the revised Maslow's hierarchy of needs? 
Maslow claims that everybody is given a unique complement of needs which are needed to be met in his/her environment so as to guide him/her in a healthy, flourishing and progressive way. These needs are set in a hierarchal order showing individuals' requirements in different stages (Maslow, 1954). Most importantly, Maslow believes that the needs which are at lower levels on the pyramid are to be met before the higher ones are achieved. Sumerlin and Charles (1998) explain "Maslow believed that self-actualizing people were healthier and lived more enriched lives than non-self-actualizing people".

Maslow (1954) has directly mentioned this in his book as follows:

Physiological needs can be considered as the most fundamental needs of human; the kinds of needs and drives which are required for human survival. Among these we can mention shelter, breathing, water and food. Secondly, safety needs are the kind of needs which produce and also ask for a sort of stability and predictability in our lives, such as personal, emotional and financial security, health, employment, and access to resources. Love and belonging needs, which are after the safety, revolve around interpersonal relationships, social interactions, friendships, family relationships, and also feelings of intimacy. The forth one, which is esteem needs, shows our needs for gaining respect, self-esteem and the desire to belong.

Lastly, the peak of the pyramid which is self-actualization refers to the condition where a person attains as all former needs have been met. Maslow himself identified no fewer than fifteen different features that a self-actualized individual may face; therefore, the precise description for a "self-actualized" state is hard to recapitulate. From the characteristics, the following can be mentioned: reception of self, others and its environment, being spontaneous, as well as autonomous and at the same time independent from the surrounding environment and the culture.

As mentioned by Maslow, the needs, or lone may call it a step in the mentioned hierarchy, would be met in an orderly manner and serves the function of a motive so that the whole needs of a given individual are met in the last level which is called self-actualization. At the same time as Maslow put emphasis on that people are normally inspired to strive for a given need in the illuminated order which ,as he mentioned, is "not nearly as rigid as we may have implied" (p. 386) plus the fact that a number of people may look for meeting the needs in a dissimilar manner.

It is needed to be mentioned striving for prosperity which is gained through self-actualization calls for a wide range of qualities such as risk taking, inquisitiveness, goal-setting and creative thinking and curiosity (Sumerlin 1997). Sumerlin also mentioned some characteristics of the non-self-actualized individuals to be "being fearful, rigid, and unfulfilled" (Sumerlin 1997, 1102). Additionally, when people have reached Maslow's concept of self-actualization, they can "function within an environment of greatest challenge where full human capacity is required and where failures provide learning experience" (Sumerlin 1997, 1105). Maslow has elaborated on self actualization as a purpose of meeting all needs following this manner:

This concept is actually somebody's aspiration to fulfill one's self, which refers to their propensity to grow actualized in what they are capable of. In a person it can be in the form of an aspiration to be a perfect mom, or it may be conveyed physically, and in a different individual it shows itself in drawing or even inventing something (Maslow, 1943).

\section{A. Significance of Maslow's Theory in Learning Environments}

The theory of Maslow's hierarchy can have a huge impact on learning contexts. So as to optimize the efficiency of school-wide and also classroom teaching programs, supervisors, teachers and managers are to take student needs into consideration. This is to be taken as a priority by authorities in order for students to be able to achieve their highest potential, that is self actualization.

\section{B. Intrinsic and Extrinsic Motivation}

Having a more profound look into the mentioned theories which are related to different kinds of motivation, it becomes clear that there two kinds of motivation which are basic to all, namely extrinsic and intrinsic. Behaviors which are motivated from inside and are intrinsically propelled are seen when there is no other perceptible pay back except the mere action itself as stated by Deci (1975). In addition to Deci (1975), two other researchers have defined it as "what people will do without external inducement." Malone and Lepper and Malone (1987). Instances of the former motivation can be a sense of accountability, hunger, even self-sacrifice, or a tendency to feel valued. On the other hand, behaviors which are extrinsically motivated are those in which the controlling mechanism can be easily seen (Deci, 1975). Instances of extrinsic motivation can be rules, rewards or money.

Deci and Ryan (1985) suggested that intrinsically motivated behaviors are actually innate and they may bring about originality, suppleness, and impulsiveness but the kind of behavior which is extrinsically motivated occurs as a result of force and may yield little self-respect and nervousness. Nevertheless, the very realization of intrinsic or extrinsic actions has always been difficult to define (Scott, 1975; Guzzo, 1979). All aside, the act of distinguishing between these two types of motivation is a vitally crucial one because of their influence on one's psyche, deeds and behaviors.

\section{Expansion of Maslow's Needs Hierarchy}

Probably, the most famous researcher who has developed Maslow's needs hierarchy into a "strong enunciation of the rudimentary expectations of the structural behavior viewpoint" (McGregor, 1957, p.133). Some notions of the manner in which the managers consider and treat their staff are brought up by McGregor (1957). A managerial supposition concerning employees is included in each theory. The most important point in McGregor's theories probably is that 
based on the common supposition, those beliefs are likely to be a completely satisfying prediction. Theory X considers employees as lazy, egocentric, foolish, and claims that guiding and dominating them is necessary. Managers with these suppositions believe that it is their responsibility to form their subordinates' job. These suppositions can lead to suspicion and finally cause a malfunction in scale. Taylor (1911) and Simon (1997) have aligned this theory in their works as they focus on organizations as totally logical systems (Scott \& Davis, 2007).

On the other hand, workers are viewed as capable, reasonable, and autonomous in Theory Y. They seek responsibility, are open to change, and desire improvement. Good work among managers with Theory Y supposition is believed to be motivating. Managers also tend to establish a more positive interpersonal relationship with their employees (McGregor, 1957).

Another theory called the motivation-hygiene theory is also developed by Hersberg (1968), who was influenced by Maslow and McGregor. In his theory, two dimensions of conditions are described: motivators and hygiene factors. Motivators, like Maslow's needs in higher-level, are those that result in job satisfaction and are often connected to the work nature: sense of achievement, appreciation, responsibility and growth. Motivators are internal elements that result in job satisfaction. Hygiene factors, On the other hand, more similar to the levels at lower levels do not actually yield satisfaction or motivation all the time, but somewhat are external and easily decrease the rate of job discontent. The policy of the corporation and management, direction, associations with managers, and labor circumstances are examples of hygiene factors.

So for example, an employee can be paid well, which is an external hygiene factor, and have good working conditions, and be satisfied. While, if she does not feel rewarded and challenged in her job, she might be dissatisfied and not motivated.

Maslow's hierarch of needs was simplified into three categories by Clayton Alderfer (1972), an American psychologist influenced by Gordon Allport (1960, 1964): Maslow's physiological and safety needs which are included in existence here; love and esteem are included in relatedness; and self-actualization is included in growth. Alderfer believed in his three categories, often abbreviated as ERG, more as a continuum instead of a strict hierarchy (Alderfer, 1969). Different people, in the ERG theory, are allowed to follow their needs at the same time and in a subjective order.

In his ERG theory, Alderfer emphasizes that if an individual's higher-level need remains unsatisfied, as it is more difficult to achieve, that individual might settle for a needs which are down the scale and are actually more conveniently met. Commonly recognized as "the frustration-regression principle", this shows itself in institutions in which an employee is frustrated with growth opportunities. Then they may start satisfying a lower level need like starting relationships with coworkers.

Some theorists believe that individuals have the same innate needs. On the other hand, David McClelland (1988) believes that a number of the mentioned needs vary in different people as these needs are often acquired; and a number of individuals have a higher level of a given need comparing to other people. It is thought that motivation is ignited in individuals based on three needs: achievement, power, and affiliation. The level of each need is different in each person and by combining them, they can explain what kind of motivation fits them.

If a worker's high-level needs are achieved, they tend to do extremely well in their job and the recognition of their efforts is appreciated. Situations with an only small gain are avoided by them, as well as situations with a high risk of failure. Employees with higher affiliation needs are more worried about their social relationships. They prefer to fit in than to stand out. And finally, individuals with high power needs tend to dominate others in order to achieve their goals. They are less worried about being recognized or approved by others.

Although there are a lot of theories based on needs, it seems quite impossible to determine which one can truly represent human needs. A great number of researchers have tried to discover different types of human needs and while many of their theories overlap in many parts, they look too many to reach a complete agreement. There are also many other theories and associated theories that have not been outlined above.

\section{METHOD}

\section{A. Participants}

This study was conducted on 271 participants, the female participants outnumbered male ones (126 male students and 145 female students). They were asked to fill out the questionnaire specifying the truth value of each statement according to their cases. Participants who have had the experience in learning English at private institute were selected randomly from B.A. students of Ferdowsi University, Imam Reza University and Tabaran Institute of higher education majoring in English literature, all semesters included. The age of the participants is between 18 and 31.

\section{B. Instrument}

The Need Satisfactory Inventory (Lester,1990) was used as the basis on which the research was held. It is in the form of questionnaire, evaluating individuals' level of needs based on Maslow's hierarchy of needs. The Need Satisfactory Inventory has five sections, each based on one level of Maslow's hierarchy of needs, namely physiological, safety, love and belonging, esteem, self-actualization. Each of these sections includes 8 or 7 statements stating relevant parameters to evaluate the need level of its subcategory.

A revised version of The Need Satisfaction Inventory (Lester,1990) questionnaire was used as an instrument to carry 
out this study. The revision was at the level of rewording and in some cases adapting some items to the English learning environment.

\section{Data Collection Procedure}

Data collection procedure took place in the first semester of the academic year 2014- 2015. 200 participants, who were in different semesters of their studies, were randomly chosen from among those who had the experience of participating in English classes. This was assured by one of the introductory items in the questionnaire filled by the participants of the study. The participants with no experience in EFL classes and those with learning experience in ESL context were omitted.

\section{Data Analysis Procedure}

In order to analyze the data collected in this study, several criteria were to be met in the procedure of data analysis. To validate and demonstrate the reliability of the revised questionnaire of the need satisfaction inventory of needs (Lester; 1990) in EFL context, used in this study, the following procedure was carried out.

\section{E. Content Validity}

The requirement of the content validity to be met was one of the concerns of the research. As the content validity is prerequisite to construct validity, the genuine attempt was to consolidate the two efficient methods of evaluating the content validity.

\section{Method 1: Average Congruency Percentage (ACP) (Popham, 1978)}

This method was designed by Popham (1978) to evaluate the content validity based on experts computing the percentage of questions deemed to be relevant. The procedure is of two steps:

First: four experts (members of academic board of English faculty) were asked to rate the relevance of each item of the questionnaire in the form of percentage.

Second: the overall percentage of each expert over the questionnaire was calculated and then summed with the other experts' estimate. If the condition of Value $>90 \%$ is met (the ACP $=90$ ) it would demonstrate an appropriate level of content validity (as stated Popham, 1978).

\section{Method 2: Content Validity Index (Martuza, 1977)}

This method was designed by Martuza (1977). It aims to evaluate the content validity at two levels, for individual items and for the scale itself. The main focus of this study at this point was the content validity of the individual items (I-CVI). To this end, a panel of subject matter experts, five faculty members of English department, Ferdowsi university of Mashhad, were asked to comment on the relevance of each question on a 4-point Likert scale. All the experts were up to answering each item as $1=$ not relevant, $2=$ somewhat relevant, $3=$ relevant, $4=$ very relevant. Afterwards, the number of experts giving 3 or 4 (relevant and very relevant) is counted for each item. The proportion is calculated, a higher value given to an item, the better the likelihood of the content validity index for that individual item.

\section{F. Construct Validity}

As it required, the first attempt here was to run the Factor Analysis. Subsequently, the inter-relationship among items were examined empirically to detect data clusters sharing the adequate level of variation in order to explain their presence as a construct which can be tapped by the revised version on Need Satisfaction Inventory questionnaire used in this study. Having found the inter-relationship among items, and gathering the items with the same amount of variation into common factors, the relation between each item and factor was also measured.

To identify the underlying relationship between measured variables the techniques that have been used were the Exploratory Factor Analysis and Confirmatory Factor Analysis. There are many topics being covered under each name of these methods. To have a clear definition of each, would be of great help here. As provided by Stevens (1996):

Exploratory factor analysis is aimed at detecting the factor structure for a number of variables, including identification of the number of factors that are present, and the pattern which is shown through factor loadings.

\section{G. Internal Consistency}

Internal consistency is a measure based on the correlations between various items in the same test. As in this study the correlation between different levels of need in the revised questionnaire of Need Satisfaction Inventory (Lester 1990) was the main focus for the internal consistency, the Cronbach's alpha was used as an estimate of consistency.

\section{RESULTS}

\section{A. Descriptive Statistics of Factors Underlying Maslow's Hierarchy of Needs}

Table 1 presents descriptive statistics of the factors underlying Maslow's hierarchy of needs in EFL contexts i.e., Physiological needs, Safety and security, Love and belonging, Esteem, and Self-actualization. 
TABLE 1.

DESCRIPTIVE STATISTICS OF FACTORS UNDERLYING MASLOW'S HIERARCHY OF NEEDS IN EFL CONTEXTS

\begin{tabular}{|lccccc|}
\hline & $\mathbf{N}$ & Minimum & Maximum & Mean & Std. Deviation \\
\hline Physiological needs & 271 & 9.00 & 40.00 & 31.73 & 6.02 \\
Safety needs & 271 & 18.00 & 50.00 & 34.45 & 6.82 \\
Love and belonging & 271 & 9.00 & 35.00 & 27 & 5.77 \\
needs & 271 & 13.00 & 50.00 & 39.07 & 9.27 \\
Esteem needs & 271 & 10.00 & 50.00 & 39.86 & 7.75 \\
S & 271 & 102.00 & 218.00 & 172.12 & 23.42 \\
Total & & & & \\
\hline
\end{tabular}

The distribution of the items with regard to the five subscales is the following: Physiological needs ( 8 items), Safety and security (10 items), Love and belonging (7 items), Esteem (10 items) and Self-actualization (10 items).

\section{B. Content Validity}

As the content validity is prerequisite to construct validity, the genuine attempt was to consolidate the two efficient methods of evaluating the content validity. To do so, Average Congruency Percentage (ACP) (Popham, 1978) was employed and Content Validity Index (Martuza, 1977). As it was presented in the result section, both procedures revealed acceptable results (Value $>90 \%$ ).

\section{Average Congruency Percentage (ACP)}

The first step in measuring the content validity is Average Congruency Percentage (ACP) designed by Popman (1978). This method evaluates the content validity of each statement in regard of its subcategory at to level. First four members of academic board of English faculty were asked to rate the relevance of each statement of the questionnaire in percentage form.

Second; the number of overall percentage of each expert over the questionnaire was estimated and summed with the other experts'. With the condition of Value $>90 \%$ being met (the ACP $=90$ ) the appropriate level of content validity was demonstrated.

TABLE 2

Average Congruency Percentage VAlues

\begin{tabular}{|l|l|}
\hline Expert & Average value \\
\hline 1 & $88 \%$ \\
\hline 2 & $91 \%$ \\
\hline 3 & $95 \%$ \\
\hline 4 & $90 \%$ \\
\hline 5 & $96 \%$ \\
\hline
\end{tabular}

In this phase, the researcher omitted 3 questions which were deemed to be irrelevant to the components specified. As well as this, the other questions were modified so as to meet a better rate of accuracy.

\section{Method 2: Content Validity Index}

This method which was designed by Martuza (1977) aims to evaluate the content validity, contrary to the first method, at two levels, for individual items and for the scale itself. The content validity of the individual items (I-CVI) is of more importance in this study. To do so, a panel of subject matter experts, five faculty members of academic board of English of Ferdowsi university of Mashhad, who also collaborated with the researcher in the former section, were asked to mark the relevance of each question on a 4-point Likert scale. All the experts were up to answering each item as $1=$ not relevant, $2=$ somewhat relevant, $3=$ relevant, $4=$ very relevant. Then the number of experts giving 3 or 4 (relevant and very relevant) was counted for each item in their categories. The proportion was calculated, a higher value given to an item, the better the likelihood of the content validity index for that individual item.

\section{Reliability Statistics}

In response to the third question, different reliability procedures were employed. The Coranbach's Alpha coefficient, the result of which was as follows. As the study was conducted on 271 participants 126 male students and 145 female students), and they were asked to filled out the questionnaire specifying the truth value of each statement according to their cases, the reliability statistics of the questionnaires data are estimated by Coranbach's Alpha on the 45 questions filled by the participants, which was .936 as follows

TABLE 3.

RELIABILITY STATISTICS

\begin{tabular}{|l|l|}
\hline Cronbach's Alpha & N of Items \\
\hline .936 & 45 \\
\hline
\end{tabular}

As it is shown in the above table, the estimate of Cronbach's Alpha of the total number of 45 items was .93, which indicates a high internal consistency of the items and the scale as whole.

Then the internal reliability of the 5 factors was also examined and they were as follow: 
TABLE 4.

THE INTERNAL CONSISTENCY OF THE FACTORS COMPRISING THE SCALE

\begin{tabular}{|l|l|l|l|}
\hline & Factor & Number of items & Coranbach's Alpha \\
\hline 1 & Physiological needs & 8 & .914 \\
\hline 2 & Safety and security & 10 & .906 \\
\hline 3 & Love and belonging & 7 & .871 \\
\hline 4 & Self esteem & 10 & .937 \\
\hline 5 & Elf actualization & 10 & .949 \\
\hline
\end{tabular}

As it is seen, the reliability of the first factor, Physiological needs, which included 8 items, was .914; the reliability of the second factor, Safety and security, which included 10 items, was .906. Likewise, the reliability of the third factor was .871 , the fourth was .937; the fifth item, which was self-actualization, included 10 items, whose reliability was .949.

\section{Construct Validity}

\section{Goodness of Fit Indices}

Goodness of Fit Indices

In order to examine the validity of the revised version of Maslow's hierarchy of needs in EFL contexts scale, the researchers employed Confirmatory Factor Analysis. Afterwards, goodness of fit indices was employed to check the model fit. in Figure 1, you can see the model including the whole factor loadings. Next, the link between sub-factors which were shown was examined, then the researchers presented the outcomes on the grounds of CFA analysis. In Table 1, Goodness of fit indices is shown. The researchers employed $\chi^{2} / \mathrm{df}$, GFI, CFI, and RMSEA in the present work. $\chi^{2} / \mathrm{df}$ is to be less than 3, GFI and TLI are to be more than 90 in order to come to a fit model; also RMSEA is to be less than .08. The whole fit indices are shown to be within the standard range, which is listed in Table 1. As a result, it can be said that the scale has the required validity.

TABLE 5.

GOODNESS OF FIT INDICES

\begin{tabular}{lllllll}
\hline & $X^{2}$ & df & X2/df & GFI & CFI & RMSEA \\
\hline Acceptable fit & & & $<3$ & $>.90$ & $>.90$ & $<.08$ \\
Model & 34.599 & 17 & 2.035 & 1.00 & .98 & .066 \\
\hline
\end{tabular}

\section{Confirmatory Factor Analysis}

As it is shown in the figure 4.1, the result of confirmatory factor analysis (CFA) is illustrated for revised version of Maslow's hierarchy of needs in EFL contexts, in which all components and extracted factors which have been confirmed are shown.

In response to the second questions, the requirements of the content validity were met here, and the scale is demonstrated to be valid in this respect, which was one of the main concerns of the research.

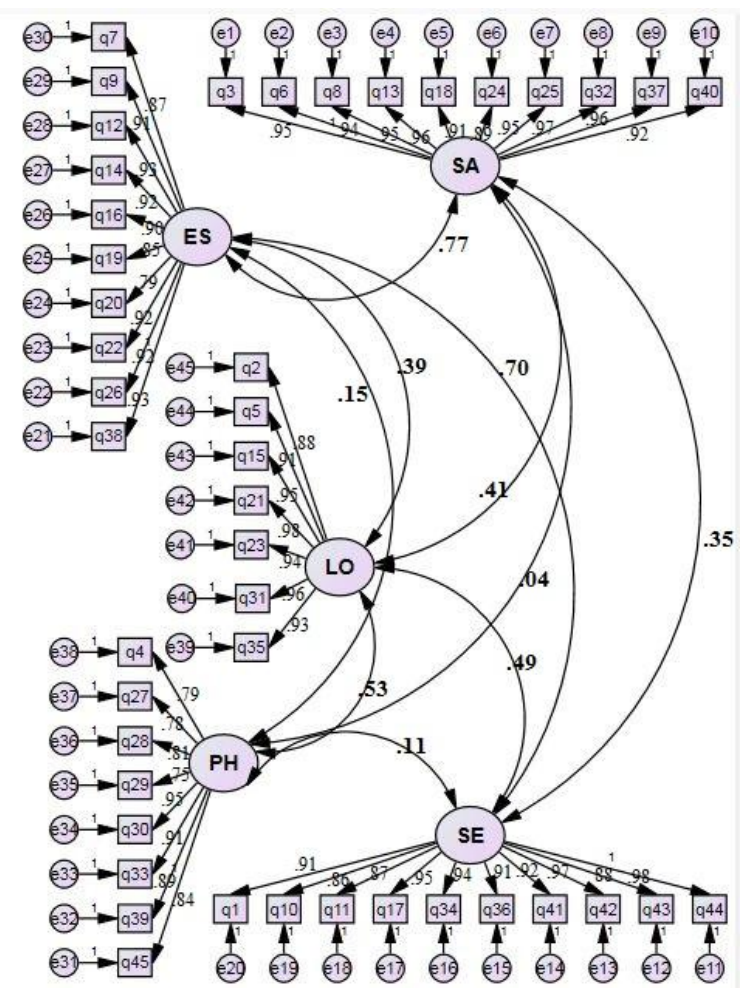

Figure 1. Results of CFA for the revised version of Maslow's hierarchy of needs in EFL contexts 


\section{CONCLUSION}

Maslow's hierarchy of needs theory, as it was seen and reviewed, could make a major contribution to teaching and classroom management in schools. Maslow (1970), himself, adopted a holistic approach to teaching and learning in general. Maslow investigated the whole physical, social, emotional, as well as intellectual features of individuals and tried to answer the question of their impact on people's life and thus education. Practical applications of Maslow's hierarchy theory to the classroom teachers and learners can be so useful. In order for a student's cognitive needs to be fulfilled, they are to meet basic physiological needs of theirs. As an instance, a worn-out student who is also hungry will naturally find it difficult to focus on learning. As well as this, students need to feel emotionally and physically safe and accepted inside the classroom to be able to improve and reach their potential.

It can be suggested that students should be shown that they are valued and respected in the classroom as a human being first, and the teacher is to establish a supportive environment. For example, students with a low self-esteem will not be able to improve academically at a best possible rate unless their self-esteem is strengthened.

As it was mentioned earlier, schools of thoughts consist of three approaches. The first one, named behaviorism, also known as structuralism in linguistics, has the idea of reinforcement and operant conditioning and anticipation of reward in enhancing motivation. The Maslow's hierarchy of needs can meet this school of thought's interest from the point that it highlighted the role of need fulfillment as a rewarding experience that would lead to reinforcement.

The second school of thought, cognitivism, points out the importance of meaningful learning, mind and human cognition. The key role of choices in the process of ego enhancement can underline the significant part of cognition in this theory and would unearth the relevance between these two (Furedy, 1991).

The last school of thought is constructivism. As the name promises, the social context plays a leading role in this approach (Ruskin, 2011). The needs and motivation concepts in many cases must be interpreted in social context that would locate the emphasis of interaction hypotheses in this hierarchy of needs.

Constructivism (Ruskin, 2011) stresses the social context besides individual personal choices. To put in other words, it can be related to both internally and externally-oriented motivation. As Maslow viewed motivation as passing through a hierarchy of basic needs to higher ones, the different context of personal and social, internal or external, can remain actively engaged in this domain.

As discussed before, constructivism is interested in individualism as well as social context. Rogerian humanistic psychology (Strupp,1955) also sheds light on individualism from both affective and cognitive aspects of human beings. The Whole person as it is named, concentrates on learners' interests and needs, and the same time it sees students as individuals who are to seek autonomy. It entitles learners to have their tailor-made styles and strategies to foster learner empowerment to change the status quo. From this view it reflects the same goal with Maslow's hierarchy of needs and motivational theories.

Two other theories which share the same history with Maslow's hierarchy of needs are Self-control theory and Drive theory (McAdams, 2015). These two theories also have some notions in common with internally-oriented motivation.

Self-control theory accentuates the role of individuals' decision or choices about their experiences and aims. This theory categorizes choices or decisions in two different contexts, namely long-term and short-term. In both terms the motivation would be boosted if one is in control of its choices and is allowed to make its own decisions. The idea of being in charge of decision making, managing and controlling is motivating and would pave the way to a better selfesteem and afterward self-actualization.

\section{DISCUSSION}

Based on the results of this study, in this section, the researcher has elaborated on the needs of students in an EFL context and has come up with practical implications of each. As it was believed by Maslow, the hierarchy of needs included five different levels in general, i.e. physiological needs, safety and security, love and belonging, self esteem and self actualization. In the following, the original definitions of each need are considered, and according to the results of this study, the needs are attributed to the needs that students may feel in a classroom environment, specifically in an EFL context.

\section{A. Physiological Needs}

Physiological Needs are considered to be the fundamental needs which human beings feel to have, such as food and water, adequate source of fresh air, etc. Normally, these needs are fulfilled for or by the learners as they take part in EFL contexts. Nonetheless, it is actually needed for students to be allowed to enjoy more time as their break and also be given a further flexible timetable in order to warrant that the requirements are met. If not, they possibly avoid the difficulties, challenges and demands that may arise so as to fulfill this lower need.

\section{B. Safety and Security Needs}

As it was mentioned in the introduction, this particular need typically pertains to a kind of personal security, in general they refer to needs such as having a shelter above, ensuring that they are safe from physical harm. Nevertheless, it can also come into EFL environments. Here, considering the results, it seems that its most important issue is to provide a caring environment that never threatens their safety needs. One can provide this environment by using stress 
relieving strategies, such as showing support from the side of teachers- as the items in the questionnaire indicateshowing learners that their speech, their feeling and their attitude is not judged by the other learners and also teachers, respecting their individuality or utilizing different sorts of techniques that makes them feel safe and secure in the class. A very useful approach to meeting their safety needs is actually to establish a support system permitting one to refer to given enquiries and issues rapidly, like an email contact form, so the students feel secure enough during the class to give themselves time to see whether they have understood the material or not, and in case they have not, they know there is a chance even after the class to contact the teacher.

\section{Love and Belonging}

As it was mentioned in the first section of the work, love and belonging is another name for the learners' social needs. Meeting a learner's social needs can be a tricky task in traditional learning environments since there are loads of tasks to be covered, and probably students' personal feelings and social behaviors are difficult to be dealt with. Yet, there are ways to trigger this level of needs, for example if a teacher incorporates more interactional and social learning activities and resources into the tasks done in the class, they have a better chance of meeting this need which naturally makes the learning experience more appealing and engaging. Based on the review of the literature that the researcher covered, it can be understood that developing group activities where learners must work together to complete a task or an assignment, such as a presentation, a gapped information activity or a role play can encourage them discuss key topics with their peers and thus engage in more social interactions. This can provide them with many chances to talk to further students in order to evade the sense of alienation, which is the key term in discussing this need.

\section{Esteem Needs}

There is one thing which has repeatedly been mentioned in different contexts, the fact that learners are to feel confident and capable in order to fulfill their self-esteem needs. Based on the results of this study, one of the most effective ways to achieve this is to develop their sense of feeling of worthiness. Doing so can increase their selfawareness, also it can provide them with an opportunity to work on the kind of expertise they are looking for by adapting to their actual and make them in control of their learning, and the fact that the environment reacts to their emotional states. Empowerment, as a matter of fact, is the key here. Students need to be allowed to choose which exercises they complete and when and even how, to some extent, and they are to be given compliments when they successfully complete a part or an exercise. This can help them greatly in boosting their confidence as well. They need to understand they are making improvements and they are being appreciated because of that.

\section{E. Self-actualization Needs}

Self-actualization is a level which is not at all easy to come by. Actually, in all aspects of life, self actualization is difficult to be achieved. In fact, some, or better to say the majority of people spend all of their lives striving to top the Maslow's Hierarchy of Needs, and their attempts are usually in vein. To help learners become self-actualized, as it was defined in the first section, it should be told to them that they are to establish lifelike goals and also try to follow their development all in the process. Teachers are to provide them with insights causing them to contemplate on their existing views and think deeply about their present presuppositions about learning and themselves. As EFL academicians, it can be said that teachers are accountable to provide learners with the means as well as the information which is required to fulfill the real potential and responsibility of theirs in the class. Consequently, they can make every effort in the direction of their individual delineation of achievement. We should remember that the concept of self-actualization actually gets to be a state which is fluid. As learners attain their objectives, they predictably look for establishing and pursuing new activities. On the other hand, it is important to emphasize the fact that they are to savor their successes before embarking on the next educational adventure. 
Appendix I. The Original InVEntory of NeEd SATISFACTiOn (LeSter, 1990)

\section{Items In The Need Satisfaction Inventory (some are phrased negatively)}

Physiological needs

(1) I never have trouble getting to sleep at night

(6) I have an income that is adequate to satisfy my needs

(ii) I get an adequate amount of rest

(16) I have a satisfactory sex life

(21) In general, my health is pood

(26) In winter, I always feel too cold

(31) I eat enough to satisfy my physiological needs

(36) I get an adequate amount of exercise

(41) There's usually some part of my body that is giving me trouble

(46) The summers are too hot for me ever to feel comfortabie

\section{Safety and security}

(2) I think the world is a pretty safe place these days

(7) I would not walk alone in my neighborhood at night

(12) My anxiety level is high

(17) I feel secure about the amount of money I have and earn

(22) I feel safe and secure

(27) I am afraid to stay in my house/apartment alone at night

(32) My life is orderly and well-defined

(37) I can depend on others to help me when I am in need

(42) I am often worried about my physical health

(47) My life has a nice routine to it

\section{Belonging}

(3) I know my family will support me and be on my side no matter what

(8) I am involved in a significant love relationship with another

(13) I feel rootless

(18) I have a group of friends with whom I do things

(23) I feel somewhat socially isolated

(28) I have a few intimate friends on whom I can rely

(33) I feel close to my relatives

(38) I am interested in my ethnic roots and feel a kinship with others in my ethnic group

(43) I am religious and consider myself to be a member of a religious group

(48) I am able to confide my innermost thoughts and feelings to at least one close and intimate friend

Estecm

(4) I feel dissatisfied with myself much of the time

(9) I foel respocted by my peers

(14) I seldom have fears that my actions will cause my friends to have a low opinion of me

(19) I can stand on my own two feet

(24) I feel confident in my present field of endeavour

(29) I would describe myself as a self-confident person

(34) I have earned the respect of others

(39) I do not spend much time worrying about what people think of me

(44) I feel that I am a worthy person

(49) In groups, I usually feel that my opinions are inferior to those of other people

\section{Self-actualization}

(5) I have a good idea of what I want to do with my life

(10) My life has meaning

(15) I am uncertain about my goals in life

(20) I feel I am living up to my potential

(25) I am secking maturity

(30) I find my work challenging

(35) I know what my capabilities are and what I can not do

(40) I feel I am doing the best I am capable of

(45) I feel that I am growing as a person

(S0) My educational achievements are appropriate given my ability 
APPEndix II. The ITEMS OF THE QUeSTIONNAIRE AND TheIr CORRESPONDING FACTORS

\section{Physiological needs}

I never have trouble focusing in classroom

I can afford the fee of English classes easily

I get an adequate period of break time during the class, if needed

In general, the physical conditions of my class are satisfactory (chairs arrangements, the board, etc.)

The class air conditioning is satisfactory

I never have trouble meeting my basic needs such as hunger and thirst during the class

I feel my classroom environment is technologically equipped

In general, I feel physically comfortable in my class

Regarding transportation, I do not face difficulty getting to the class

\section{Safety and security}

I believe the class is a safe place in general

I feel safe to talk about my personal ideas

My anxiety level is low

I feel secure about my knowledge in English

I feel safe against opposing attitudes from my peers

I believe my grades are true reflection of my knowledge, not just a subjective opinion of my teacher My learning process is orderly and well-defined

I can depend on others to help me when I am in need

I am often worried about my image as a student/classmate

My class has a nice routine to it

\section{Love and belonging}

I know my teacher and my classmates will support me, no matter what

I am involved in a friendly relationship with my classmates

I feel I can relate to the learning atmosphere in my class

I have group of friends with whom I do things

I do not feel socially isolated

I feel close to my teacher

I believe my personal thoughts are welcome in the class

\section{Esteem}

I feel satisfied with myself much of the time

I feel respected by my peers

I do not have fears that my English skills will cause my friends to have a low opinion of me

I can stand on my own English knowledge

I feel confident in my present efforts

I would describe myself as a self confident learner

I have earned the respect of my classmates

I do not spend much time worrying about what my classmates think of me

I feel that I am a worthy person in the class

In groups, I usually feel that my opinions are superior to those of others

\section{Self actualization}

I have a good idea of why I am learning English

English means a lot to me

I am certain about my goals in my learning process

I feel I am living up to my potential in English

I am seeking proficiency

I enjoy challenging tasks in English

I know what my capabilities are and what I cannot do

I feel I am doing the best I am capable of in learning

I feel I am growing as a person because of learning English

My achievements in English are appropriate given my ability 
APPENDiX III. The QUeSTIONNAIRE USED IN THE STUDY



\section{REFERENCES}

[1] Ashton, P. T. (1985). Motivation and the teacher's sense of efficacy. In: Ames, C. and Ames, R. (eds.) Research on motivation in education, Orlando, FL: Academic Press, 141-171.

[2] Alderfer, C. P. (1969). An empirical test of a new theory of human needs. Organizational behavior and human performance, 4 , $142-175$.

[3] Alderfer, C. P. (1972). Existance, Relatedness, and Growth: Human Needs in Organizational Settings. New York: Free Press. 
[4] Allport, G. W. (1960). Personality and social encounter: Selected essays. Boston: Beacon Press.

[5] Allport, G. W. (1964). Pattern and growth in personality. New York: Holt, Rinehart and Winston.

[6] Deci, E. L. (1975). Intrinsic Motivation. New York: Plenum Press.

[7] Deci, E. L. \& Ryan, R. M. (1985). Intrinsic motivation and self-determination in human behavior. New York: Plenum Press.

[8] Deci, E. L. \& Ryan, R. M. (2000). The "what" and "why" of goal pursuits: Human needs and the self-determination of behavior. Psychological Inquiry, 11, 227-268.

[9] Furedy, J.J. (1991). Cognitivism and the conflict between realist and instrumentalist approaches to scientific reasoning. Canadian Psychology/Psychologie canadienne, 32, 461-463.

[10] Gregg, W. E. (1971, February). Graduate student satisfaction: Academic and non-academic. Paper presented at the 55th Annual Meeting of the American Educational Research Association, New York.

[11] Guzzo, R. A. (1979). Types of rewards, cognitions, and work motivation. Academy of Management Review.

[12] Lepper, M. R., \& Malone, T. W. (1987). Intrinsic motivation in the classroom. Research on motivation in education. In R. E Snow \& M. J. Farr (Eds.) Aptitude, Learning and instruction: Vol. 3. Conative and affective process analyses (pp. 225-286). Hillsdale, NJ: Erlbaum.

[13] Maslow, A. (1946). A theory of human motivation. Psychological Review, 50, 370-396.

[14] Maslow, A. H. (1970b). Religions, values, and peak experiences. New York: Penguin. (Original work published 1964)

[15] McAdams, D. P. (2015). Three lines of personality development: A conceptual itinerary. European Psychologist, 20(4), 252264.

[16] McGregor, D. (1957). The human side of enterprise. Management Review, 22-28, 88-92.

[17] Simon, H. A. (1997). Administrative Behavior, 4th Edition. New York: Free Press.

[18] Strupp, H. H. (1955). An Objective Comparison of Rogerian and Psychoanalytic Techniques. Journal of Consulting Psychology, 19(1), 1-7.

[19] Svanes, B. (1984). "Motivation and Cultural Distance in Second-language Acquisition". Language Learning, 3, $341-359$.

[20] Sumerlin, J. R., \& Bundrick, C. M. (1998). Revision of the Brief Index of Self-Actualization. Perceptual and Motor Skills, $87(1), 115-125$.

[21] Taylor, F. W. (1911). The Principles of Scientific Management. New York: Norton.

Zahra Barzakhi Farimani was born and brought up in Mashhad, 1992. Having acquired her degree in English literature at Ferdowsi university of Mashhad, she was admitted into the master's program of English teaching at Fedowsin University of Mashhad, Iran in 2014. In 2017 after graduation, she started doing her Ph.D. in TEFL at the same university.

She is an experienced academician, who has been teaching different levels of English for more than 9 years as a freelance teacher.

Her research interests lie in the fields of psychology, cognitive science and material development.

Dr. Barzakhi Farimani has collaborated with the journal of Research in English Language Pedagogy and the World Council for Curriculum and Instruction (WCCI) as an author and reviewer.

Navid Nasrollahi Shahri was born in Mashhad, 1991, and gained his Bachelor's degree in English literature from Ferdowsi University of Mashhad, Iran in 2014. He did his master's in English Teaching at the same university and in 2017, started his Ph.D. program at university of Shiraz, Iran.

$\mathrm{He}$, as a professional teacher, researcher and translator, has been teaching English since the beginning of his academic life, and has contributed to many research projects related to the field of curriculum development. His research interests are sociocultural theory, psycholinguistics and teacher training programs.

Dr. Nasrollahi Shahri is an active member of the academic community working as a reviewer for the journal of SiELE at Unsyiah University. He is a published author, professional researcher and avid teacher. 